\title{
Genetic characterization, species differentiation and detection of Fasciola spp. by molecular approaches
}

Lin $\mathrm{Ai}^{1,2,3+}$, Mu-Xin Chen ${ }^{1,2+}$, Samer Alasaad ${ }^{4}$, Hany M Elsheikha ${ }^{5}$, Juan $\mathrm{Li}^{3}$, Hai-Long Li ${ }^{3}$, Rui-Qing Lin ${ }^{3}$, Feng-Cai Zou ${ }^{6}$, Xing-Quan Zhu ${ }^{1,6,7^{*}}$ and Jia-Xu Chen ${ }^{2^{*}}$

\begin{abstract}
Liver flukes belonging to the genus Fasciola are among the causes of foodborne diseases of parasitic etiology. These parasites cause significant public health problems and substantial economic losses to the livestock industry. Therefore, it is important to definitively characterize the Fasciola species. Current phenotypic techniques fail to reflect the full extent of the diversity of Fasciola spp. In this respect, the use of molecular techniques to identify and differentiate Fasciola spp. offer considerable advantages. The advent of a variety of molecular genetic techniques also provides a powerful method to elucidate many aspects of Fasciola biology, epidemiology, and genetics. However, the discriminatory power of these molecular methods varies, as does the speed and ease of performance and cost. There is a need for the development of new methods to identify the mechanisms underpinning the origin and maintenance of genetic variation within and among Fasciola populations. The increasing application of the current and new methods will yield a much improved understanding of Fasciola epidemiology and evolution as well as more effective means of parasite control. Herein, we provide an overview of the molecular techniques that are being used for the genetic characterization, detection and genotyping of Fasciola spp..
\end{abstract}

\section{Background}

Fascioliasis is an important food-and water-borne parasitic zoonosis caused by liver flukes of the genus Fasciola (Platyhelminthes: Digenea: Fasciolidae) [1,2]. Fasciola spp. have a cosmopolitan distribution, with high frequency in tropical areas $[1,3,4]$. Human fascioliasis has been reported in numerous countries $[1,3,5]$. It is estimated that millions of people are infected worldwide and the number of people at risk exceeds 180 million [6]. Also, fascioliasis is one of the most important parasitic diseases in grazing animals with over 700 million production animals being at risk of infection and economic

\footnotetext{
*Correspondence: xingquanzhu1@hotmail.com; chenjiaxu1962@163.com + Contributed equally

'State Key Laboratory of Veterinary Etiological Biology, Key Laboratory of Veterinary Parasitology of Gansu Province, Lanzhou Veterinary Research Institute, CAAS, Lanzhou, Gansu Province 730046, P R China

${ }^{2}$ National Institute of Parasitic Diseases, Chinese Center for Disease Control and Prevention, Shanghai 200025, P R China Full list of author information is available at the end of the article
}

losses were estimated at > US\$ 2 billion per year worldwide [6].

A few species have been described within the genus Fasciola, but only three species, Fasciola hepatica, Fasciola gigantica and Fasciola jacksoni are commonly recognized as taxonomically valid, with $F$. hepatica mainly occurring in temperate areas, F. gigantica in tropical zones, and both taxa overlapping in subtropical areas [6-11]. F. jacksoni is known as the fasciolid of Asian elephants and its phylogenetic position is still uncertain [12]. Given the adverse impact of Fasciola infection on human health and its economic significance, rapid and accurate identification of Fasciola species is necessary for successful clinical management of infection, and for epidemiological surveys.

For a long time, the identification of Fasciola spp. has been based solely on traditional morphological approaches. However, due to the limitations of morphological methods, various molecular approaches have been developed and used for the identification and differentiation of Fasciola
C Biomed Central 
species. Importantly, these molecular methods have raised questions and spurred debate on the recognition of the "intermediate Fasciola" as a hybrid/introgressed form between F. hepatica and F. gigantica [8,13-20]. This hybrid Fasciola represents the emergence of a natural diversity previously undetected using conventional approaches, probably because of the inadequacy of their discriminatory power.

This article reviews molecular techniques used to identify and detect genetic variation among Fasciola spp.

\section{The identification and recognition of the "intermediate Fasciola"}

A number of genetic and phylogenetic studies (Table 1) using different molecular targets have shown the existence of novel "intermediate Fasciola" [13-19,21-23]. Ribosomal DNA (rDNA) is one of the most useful markers in genetic studies because it is available in high copy number and contains variable regions flanked by more conserved regions [24]. Previous studies have demonstrated that the first and second internal transcribed spacers (ITS-1 and ITS-2) of rDNA located between the nuclear small and large subunit rRNA genes can provide genetic markers for species-level identification of Fasciola [14,18,21,22,25] (Table 1). The ITS-2 sequence motifs were considered the DNA barcodes for Fasciola spp. [26]. Comparing ITS-2 sequences, six sites at which F. gigantica and F. hepatica differ were found, and one of these is a deletion in F. gigantica relative to $F$. hepatica $[18,22,25,27]$. Whereas, the "intermediate Fasciola" has nucleotides shared between the two Fasciola species. In agreement with results obtained by using ITS2 sequences, $F$. gigantica was found to be different from $F$. hepatica at five nucleotide positions in the ITS-1 sequences, whereas the "intermediate Fasciola" has the ITS-1 sequence of both F. gigantica and F. hepatica $[15-17,21]$. In addition to the ITS sequences, the D2 region of $28 \mathrm{~S}$ rDNA provided genetic evidence for the existence of natural hybridization between F. gigantica and F. hepatica in Korea [18].

Table 1 Summary of molecular approaches used for the detection and/or genetic differentiation of Fasciola spp..

\begin{tabular}{|c|c|c|c|c|c|c|c|c|}
\hline \multirow{2}{*}{$\begin{array}{l}\text { Molecular } \\
\text { approach }\end{array}$} & \multicolumn{3}{|c|}{ Species investigated } & \multicolumn{3}{|c|}{ Developmental stage } & \multirow[t]{2}{*}{ DNA target regions } & \multirow[t]{2}{*}{ References } \\
\hline & F. hepatica & F. gigantica & $\begin{array}{l}\text { Intermediate } \\
\text { form }\end{array}$ & Adult & Cercaria & Eggs & & \\
\hline \multirow[t]{13}{*}{ Conventional PCR } & $\sqrt{ }$ & & & $\sqrt{ }$ & & & ITS2 & 38 \\
\hline & $\sqrt{ }$ & $\sqrt{ }$ & $\sqrt{ }$ & $\sqrt{ }$ & & & ITS2 & 14,27 \\
\hline & $\sqrt{ }$ & $\sqrt{ }$ & & $\sqrt{ }$ & & & ITS1, ITS2 & 25 \\
\hline & $\sqrt{ }$ & & & $\sqrt{ }$ & & & nad1, cox1 & 28 \\
\hline & $\sqrt{ }$ & $\sqrt{ }$ & $\sqrt{ }$ & $\sqrt{ }$ & & & nad1, cox1 & 13,17 \\
\hline & $\sqrt{ }$ & $\sqrt{ }$ & $\sqrt{ }$ & $\sqrt{ }$ & & & ITS2, cox 1 & 9 \\
\hline & $\sqrt{ }$ & $\sqrt{ }$ & $\sqrt{ }$ & $\sqrt{ }$ & & & ITS1, nad1 & 16 \\
\hline & $\sqrt{ }$ & $\sqrt{ }$ & $\sqrt{ }$ & $\sqrt{ }$ & & & cox1, ITS1, ITS2 & 15 \\
\hline & $\sqrt{ }$ & $\sqrt{ }$ & $\sqrt{ }$ & $\sqrt{ }$ & & & nad1, cox1, ITS2, $28 \mathrm{~S}$ & 18 \\
\hline & $\sqrt{ }$ & & & $\sqrt{ }$ & & & Complete mitochondrial genome & 30 \\
\hline & & $\sqrt{ }$ & & & $\sqrt{ }$ & & 124 bp repetitive DNA sequence & 49 \\
\hline & $\sqrt{ }$ & & & & $\sqrt{ }$ & & 124 bp repetitive DNA sequence & 50 \\
\hline & $\sqrt{ }$ & & & $\sqrt{ }$ & & & 285 & 39 \\
\hline Multiplex PCR & $\sqrt{ }$ & & & & $\sqrt{ }$ & & cox1, ITS1, ITS2 & 52 \\
\hline Specific PCR & $\sqrt{ }$ & $\sqrt{ }$ & $\sqrt{ }$ & $\sqrt{ }$ & $\sqrt{ }$ & $\sqrt{ }$ & ITS2 & 47 \\
\hline \multirow[t]{3}{*}{ PCR-RFLP } & $\sqrt{ }$ & $\sqrt{ }$ & $\sqrt{ }$ & $\sqrt{ }$ & & & ITS2 & 22 \\
\hline & & $\sqrt{ }$ & & $\sqrt{ }$ & & & $\operatorname{cox} 1$, ITS2 & 23 \\
\hline & $\sqrt{ }$ & $\sqrt{ }$ & $\sqrt{ }$ & $\sqrt{ }$ & & & ITS1 & 8,21 \\
\hline PCR-SSCP & $\sqrt{ }$ & $\sqrt{ }$ & & $\sqrt{ }$ & & & Repetitive DNA sequences & 46 \\
\hline \multirow[t]{2}{*}{ RAPD-PCR } & & $\sqrt{ }$ & & $\sqrt{ }$ & & & Random nucleotide sequence & 43 \\
\hline & $\sqrt{ }$ & $\sqrt{ }$ & $\sqrt{ }$ & $\sqrt{ }$ & & & Random nucleotide sequence & 53 \\
\hline \multirow[t]{2}{*}{ SRAP } & $\sqrt{ }$ & & & $\sqrt{ }$ & & & Random nucleotide sequence & 42 \\
\hline & $\sqrt{ }$ & $\sqrt{ }$ & $\sqrt{ }$ & $\sqrt{ }$ & & & Random nucleotide sequence & 10 \\
\hline DNA probe & & $\sqrt{ }$ & & & $\sqrt{ }$ & & Repetitive DNA fragments & 48 \\
\hline TaqMan real-time PCR & $\sqrt{ }$ & $\sqrt{ }$ & $\sqrt{ }$ & $\sqrt{ }$ & & & ITS2 & 54 \\
\hline LAMP & $\sqrt{ }$ & $\sqrt{ }$ & $\sqrt{ }$ & $\sqrt{ }$ & $\sqrt{ }$ & $\sqrt{ }$ & IGS & 58 \\
\hline PCR & $\sqrt{ }$ & & & $\sqrt{ }$ & & & Microsatellites & 59 \\
\hline
\end{tabular}


Other molecular markers being used frequently are mitochondrial DNA (mtDNA) sequences. Almost all of eukaryotes contain a mitochondrial genome which evolves at a faster rate than the nuclear genome and, is thus suitable for discriminating closely related organisms [28-30], especially at the species and sub-species levels [31-33]. mtDNA sequence analysis also provided evidence for the existence of the "intermediate Fasciola" $[15,16,19]$.

\section{Genetic variation among and within Fasciola spp}

Revealing genetic variation has been the focus of many studies because accurate analysis of genetic variability has important implications for studying population biology, epidemiology, and genetic structure of these parasites, and thus the efficient control of the diseases they cause.

Examination of Fasciola specimens from geographical areas where $F$. hepatica and F. gigantica co-exist, such as Egypt and Iran, demonstrated the existence of phenotypic variations in adult flukes [20,34]. Molecular approaches utilizing a number of genetic makers are useful for genetic characterization and studies of genetic variability among parasite populations [35-37]. A recent study investigated the extent of genetic variation among Fasciola collected from different host species and geographical localities in Spain using ITS rDNA as genetic markers, and concluded that only a single species $F$. hepatica exists in Spain, although a slight sequence variation in the ITS-2 was detected among $F$. hepatica samples from different host species and geographical areas [38]. Spanish F. hepatica examined in that study differed from $F$. hepatica from elsewhere by two nucleotides in the ITS-2 [38]. Another study detected some genetic variations in $F$. hepatica from northwest of Spain using the $28 \mathrm{~S}$ rDNA as genetic marker, and there were nucleotide differences in a number of sequence positions [39].

Sequence related amplified polymorphism (SRAP) is a molecular technique for detecting genetic variation in the open reading frames (ORFs) of genomes of related organisms $[40,41]$. A recent study showed that the SRAP technique was useful for revealing genetic variability within and between $F$. hepatica, F. gigantica and the "intermediate Fasciola", which substantiated the evidence for the existence of the "intermediate Fasciola" [10]. Using the same technique, genetic variability among a number of $F$. hepatica samples collected from six host species and 16 geographical locations in Spain was investigated [42], and a low genetic variation in the coding regions of the genomes was found, indicating the lack of genetic association between $F$. hepatica and their hosts and/or geographical locations in Spain [42].
Randomly amplified polymorphic DNA (RAPD) is a useful genetic marker for the identification and genetic characterization of parasite populations [37]. RAPD is a useful technique for the identification and differentiation of $F$. hepatica and F. gigantica. Using the RAPD technique, some degree of genetic variation was detected among $F$. gigantica isolates from cattle, buffalo, and goat. Cattle and buffalo isolates of $F$. gigantica showed $100 \%$ homogeneity, whereas goat and cattle/buffalo isolates displayed $92.68 \%$ similarity [43].

mtDNA sequences provided useful markers for studies of genetic variability and population structures $[28,44]$. Walker et al. (2007) examined DNA polymorphism in the entire mitochondrial genome and showed that genetic diversity exist among and within $F$. hepatica populations from cattle and sheep and provided evidence for the existence of multiple mitochondrial lineages within infra-populations of $F$. hepatica [44]. Another study examined genetic variation in eastern European and western Asian populations of F. hepatica using partial mitochondrial NADH dehydrogenase subunits 1 ( $\mathrm{ad} 1$ ) and cytochrome $c$ oxidase subunit 1 gene ( $\operatorname{cox} 1)$ as genetic markers, and revealed the existence of two well-defined lineages with two main haplotypes and a number of shared divergent haplotypes among the examined $F$. hepatica populations [28].

\section{Molecular detection and identification of Fasciola spp}

In order to overcome the limitation of the phenotypic methods, genotypic approaches have been used for the identification and differentiation of Fasciola spp. [9,10,21,22,45-47]. Before the availability of PCR-based approaches, DNA probes were the alternative choice for the genotypic detection of Fasciola spp. [48]. However, DNA probe-based assays usually require the use of radioactive isotopes and can have bio-safety concerns.

Over the last two decades, several PCR-based approaches (Table 1), including PCR-linked restriction fragment length polymorphism (PCR-RFLP), PCR-linked single-strand conformation polymorphism (PCR-SSCP) and specific PCR assays, have been developed for the accurate identification of Fasciola spp. [8,21,22,45,46]. For example, a simple and rapid PCR-RFLP assay targeting a 618-bp sequence of the $28 \mathrm{~S}$ rDNA was developed for the differentiation between $F$. hepatica and $F$. gigantica [45]. A similar PCR-RFLP assay using restriction endonucleases $H s p 92$ II and Rca I was developed to differentiate between F. hepatica, F. gigantica and the "intermediate Fasciola" in China utilizing the ITS-2 rDNA as genetic marker [22]. Using the ITS-1 rDNA as genetic marker, Lin et al. (2007) established a PCR-SSCP assay for the accurate identification and differentiation between $F$. hepatica, F. gigantica and the "intermediate Fasciola" [21]. A very recent study 
established a fluorescence-based SSCP (F-PCR-SSCP) for the identification of Fasciola spp. [46].

Recently, several specific PCR assays have been developed to differentiate $F$. hepatica from $F$. gigantica and detect Fasciola infections in the intermediate host snail and definitive hosts (such as buffalo), utilizing various genetic markers, such as cox1, ITS, non-coding repetitive DNA fragment as well as RAPD-derived sequences [47,49-53]. For example, Ai et al. (2010) established a specific PCR method based on the ITS-2 sequences to identify $F$. hepatica, F. gigantica and the "intermediate Fasciola". The method was sensitive as it was able to amplify target DNA fragment from a single Fasciola egg [47]. Specific PCR assays, using two primer sets derived from RAPD-derived sequences from English $F$. hepatica and Ghanaian F. gigantica, were able to distinguish $F$. hepatica from $F$. gigantica from cattle and sheep hosts from different countries [53]. Alasaad et al. (2011) developed a highly specific, sensitive, and simple TaqMan-based real-time PCR assay for the identification of F. hepatica and F. gigantica, as well as the "intermediate Fasciola" based on sequences of the ITS-2 rDNA [54].

A PCR assay was used to detect $F$. gigantica infection in the snail vector host, Lymnaea auricularia [49]. The specific primers amplified a $F$. gigantica specific $124-\mathrm{bp}$ non-coding repetitive DNA fragment from infected L. auricularia snails. Kaplan et al. (1995) also identified a 124-bp repetitive DNA sequence which was used as a specific probe for detection of $F$. hepatica infections in intermediate host snails (Fossaria cubensis and Pseudosuccinea columella) [51]. A multiplex PCR assay was able to detect $F$. hepatica DNA in L. viatrix snails, which were even formalin-fixed and paraffin-embedded [52]. TaqMan chemistry was adopted by Schweizer et al. (2007) to establish a real-time PCR assay. The combined use of primers and probe targeting an 86-bp target of a repetitive 449-bp genomic DNA fragment facilitated the detection of L. truncatula naturally infected with F. hepatica. These PCR assays are highly specific and sensitive, providing useful and practical tools for the epidemiological investigation of Fasciola in the snail hosts [55].

Loop-mediated isothermal amplification (LAMP) allows amplification of target nucleic acids under isothermal conditions with high sensitivity, specificity, rapidity and precision, which has found broad applications for the detection of pathogens [56,57]. Ai et al. (2010) developed a LAMP assay for the sensitive and rapid detection and discrimination of $F$. hepatica and F. gigantica. The assay can be done in 45 min under isothermal conditions at $61^{\circ} \mathrm{C}$ or $62^{\circ} \mathrm{C}$ by employing a set of 4 species-specific primer mixtures and the results can be checked visually. This LAMP assay was approximately $10^{5}$ times more sensitive than the conventional specific PCR assays, and may find applicability in the field settings or in poorly-equipped laboratories in endemic countries [58].

\section{Conclusions and future perspectives}

Much of the current knowledge of Fasciola spp. taxonomy and epidemiology has stemmed from numerous observational and morphological studies. However, conventional methods of detection and differentiation of Fasciola do not accurately reflect the full diversity of Fasciola spp. Nevertheless, molecular genetics studies over the past two decades have added significantly to our understanding of Fasciola taxonomy, genetics, and contributed to the development of advanced approaches for the accurate identification and differentiation of Fasciola spp. Importantly, these molecular methods have facilitated the identification of the hybrid "intermediate Fasciola". However, presently there is no molecular diagnostic method (e.g. a Copro-PCR) developed and validated for use with human stools.

We are still far from a complete understanding of the molecular evolution of the hybrid Fasciola, and many questions remain unanswered. For example, what is the outcome of experimental crosses between $F$. hepatica and $F$. gigantica? What are the differences between the "intermediate Fasciola" and other Fasciola species at the genomic and transcriptomic levels? Comprehensive genetic characterization using more variable markers such as microsatellites (eg. [59]) along with transcriptional analysis of Fasciola species can be used to refine the taxonomic status of the "intermediate Fasciola" and to assess its potential as a zoonotic agent.

On the analytical methods front, there is a clear need for the application of high-throughput molecular techniques such as next-generation sequencing, transcriptomics, proteomics and large-scale analysis of single nucleotide polymorphisms. The successful application of these and other techniques should bring more insights into the population genetic structure and the evolutionary process in Fasciola.

Recently, there have been increasing interests in the studies of transcriptome and proteome of $F$. hepatica [60-62]. More studies in these promising areas of research will expand our understanding of the complex biology of different Fasciola species, which, in turn, will facilitate the development of novel means of therapeutic and immunological intervention.

\section{Acknowledgements}

This work was supported, in part, by the National S \& T Major Program (Grant No. 2008ZX10004-011, 2009ZX10004-302, 2009ZX10004-201), the National Key Technology R \& D Program (Grant No. 2008BAI56B03), the State Key Laboratory of Veterinary Etiological Biology, Lanzhou Veterinary Research Institute, Chinese Academy of Agricultural Sciences, the Yunnan Provincial Program for Introducing High-level Scientists (Grant No. 2009CI125) and the 
Program for Changjiang Scholars and Innovative Research Team in University (Grant No. IRT0723).

\section{Author details}

${ }^{1}$ State Key Laboratory of Veterinary Etiological Biology, Key Laboratory of Veterinary Parasitology of Gansu Province, Lanzhou Veterinary Research Institute, CAAS, Lanzhou, Gansu Province 730046, P R China. ${ }^{2}$ National Institute of Parasitic Diseases, Chinese Center for Disease Control and Prevention, Shanghai 200025, P R China. ${ }^{3}$ College of Veterinary Medicine, South China Agricultural University, Guangzhou, Guangdong Province 510642, P R China. ${ }^{4}$ Estación Biológica de Doñana, Consejo Superior de Investigaciones Científicas (CSIC), Avda. Américo Vespucio s/n 41092 Sevilla, Spain. ${ }^{5}$ School of Veterinary Medicine and Science, University of Nottingham, Sutton Bonington Campus, Loughborough, LE12 5RD, UK. ${ }^{6}$ College of Animal Science and Technology, Yunnan Agricultural University, Kunming, Yunnan Province 650201, P R China. ${ }^{7}$ College of Animal Science and Veterinary Medicine, Heilongjiang Bayi Agricultural University, Daqing, Heilongjiang Province 163319, P R China.

\section{Authors' contributions}

XQZ, JXC, SA and HME conceived and designed the review, and critically revised the manuscript. $L A$ and $M X C$ drafted the manuscript. JL, $H L L, R Q L$ and FCZ contributed to drafting the manuscript. All authors read and approved the final manuscript.

\section{Competing interests}

The authors declare that they have no competing interests.

Received: 19 March 2011 Accepted: 10 June 2011

\section{Published: 10 June 2011}

\section{References}

1. S Mas-Coma, MD Bargues, MA Valero, Fascioliasis and other plant-borne trematode zoonoses. Int J Parasitol. 35, 1255-1278 (2005). doi:10.1016/j. ijpara.2005.07.010

2. P Zhou, N Chen, RL Zhang, RQ Lin, XQ Zhu, Food-borne parasitic zoonoses in China: perspective for control. Trends Parasitol. 24, 190-196 (2008). doi:10.1016/j.pt.2008.01.001

3. MS Mas-Coma, JG Esteban, MD Bargues, Epidemiology of human fascioliasis: a review and proposed new classification. Bull World Health Organ. 77, 340-346 (1999)

4. TW Spithill, JP Dalton, Progress in development of liver fluke vaccines. Parasitol Today. 14, 224-228 (1998). doi:10.1016/S0169-4758(98)01245-9

5. TH Le, NV De, T Agatsuma, D Blair, J Vercruysse, P Dorny, TG Nguyen, DP McManus, Molecular confirmation that Fasciola gigantica can undertake aberrant migrations in human hosts. J Clin Microbiol. 45, 648-650 (2007). doi:10.1128/JCM.01151-06

6. S Mas-Coma, MA Valero, MD Bargues, Fasciola, lymnaeids and human fascioliasis, with a global overview on disease transmission, epidemiology, evolutionarygenetics, molecular epidemiology and control. Adv Parasitol. 69, 41-146 (2009)

7. IW Caple, MR Jainudeen, TD Buick, CY Song, Some clinico-pathologic findings in elephants (Elephas maximus) infected with Fasciola Jacksoni. J Wildl Dis. 14, 110-115 (1978)

8. M Ichikawa, T Itagaki, Discrimination of the ITS1 types of Fasciola spp. based on a PCR-RFLP method. Parasitol Res. 106, 757-761 (2010). doi:10.1007/ s00436-010-1724-2

9. TG Nguyen, N Van De, J Vercruysse, P Dorny, TH Le, Genotypic characterization and species identification of Fasciola spp. with implications regarding the isolates infecting goats in Vietnam. Exp Parasitol. 123, 354-361 (2009). doi:10.1016/j.exppara.2009.09.001

10. QY Li, SJ Dong, WY Zhang, RQ Lin, CR Wang, DX Qian, ZR Lun, HQ Song, $X Q$ Zhu, Sequence-related amplified polymorphism, an effective molecular approach for studying genetic variation in Fasciola spp. of human and animal health significance. Electrophoresis. 30, 403-409 (2009). doi:10.1002/ elps.200800411

11. F Kramer, T Schnieder, Sequence heterogeneity in a repetitive DNA element of Fasciola. Int J Parasitol. 28, 1923-1929 (1998). doi:10.1016/500207519(98)00162-3

12. WM Lotfy, SV Brant, RJ DeJong, TH Le, A Demiaszkiewicz, RP Rajapakse, VB Perera, JR Laursen, ES Loker, Evolutionary origins, diversification, and biogeography of liver flukes (Digenea, Fasciolidae). Am J Trop Med Hyg. 79, 248-255 (2008)

13. T Itagaki, KI Tsutsumi, K Ito, Y Tsutsumi, Taxonomic status of the Japanese triploid forms of Fasciola: comparison of mitochondrial ND1 and COI sequences with F. hepatica and F. gigantica. J Parasitol. 84, 445-448 (1998). doi:10.2307/3284510

14. T Itagaki, K Tsutsumi, Triploid form of Fasciola in Japan: genetic relationships between Fasciola hepatica and Fasciola gigantica determined by ITS-2 sequence of nuclear rDNA. Int J Parasitol. 28, 777-781 (1998). doi:10.1016/50020-7519(98)00037-X

15. T Itagaki, M Kikawa, K Sakaguchi, J Shimo, K Terasaki, T Shibahara, K Fukuda, Genetic characterization of parthenogenic Fasciola sp. in Japan on the basis of the sequences of ribosomal and mitochondrial DNA. Parasitology. 131, 679-685 (2005). doi:10.1017/S0031182005008292

16. T Itagaki, M Kikawa, K Terasaki, T Shibahara, K Fukuda, Molecular characterization of parthenogenic Fasciola sp. in Korea on the basis of DNA sequences of ribosomal ITS1 and mitochondrial NDI gene. J Vet Med Sci. 67, 1115-1118 (2005). doi:10.1292/jvms.67.1115

17. T Itagaki, K Sakaguchi, K Terasaki, O Sasaki, S Yoshihara, T Van Dung, Occurrence of spermic diploid and aspermic triploid forms of Fasciola in Vietnam and their molecular characterization based on nuclear and mitochondrial DNA. Parasitol Int. 58, 81-85 (2009). doi:10.1016/j. parint.2008.11.003

18. T Agatsuma, Y Arakawa, M Iwagami, Y Honzako, U Cahyaningsih, SY Kang, SJ Hong, Molecular evidence of natural hybridization between Fasciola hepatica and F. gigantica. Parasitol Int. 49, 231-238 (2000). doi:10.1016/ S1383-5769(00)00051-9

19. TH Le, NV De, T Agatsuma, NT Thi, QD Nguyen, DP McManus, D Blair, Human fascioliasis and the presence of hybrid/introgressed forms of Fasciola hepatica and Fasciola gigantica in Vietnam. Int J Parasitol. 38, 725-730 (2008). doi:10.1016/j.jpara.2007.10.003

20. K Ashrafi, MA Valero, M Panova, MV Periago, J Massoud, S Mas-Coma, Phenotypic analysis of adults of Fasciola hepatica, Fasciola gigantica and intermediate forms from the endemic region of Gilan, Iran. Parasitol Int. 55, 249-260 (2006). doi:10.1016/j.parint.2006.06.003

21. RQ Lin, SJ Dong, K Nie, CR Wang, HQ Song, AX Li, WY Huang, XQ Zhu, Sequence analysis of the first internal transcribed spacer of rDNA supports the existence of the intermediate Fasciola between $F$. hepatica and $F$. gigantica in mainland China. Parasitol Res. 101, 813-817 (2007). doi:10.1007/ s00436-007-0512-0

22. WY Huang, B He, CR Wang, XQ Zhu, Characterisation of Fasciola species from mainland China by ITS-2 ribosomal DNA sequence. Vet Parasitol. 120, 75-83 (2004). doi:10.1016/j.vetpar.2003.12.006

23. K Hashimoto, T Watanobe, CX Liu, I Init, D Blair, S Ohnishi, T Agatsuma, Mitochondrial DNA and nuclear DNA indicate that the Japanese Fasciola species is F. gigantica. Parasitol Res. 83, 220-225 (1997)

24. NB Chilton, The use of nuclear ribosomal DNA markers for the identification of bursate nematodes (order Strongylida) and for the diagnosis of infections. Anim Health Res Rev. 5, 173-187 (2004). doi:10.1079/AHR200497

25. H Ali, L Ai, HQ Song, S Ali, RQ Lin, B Seyni, G Issa, XQ Zhu, Genetic characterisation of Fasciola samples from different host species and geographical localities revealed the existence of $F$. hepatica and $F$. gigantica in Niger. Parasitol Res. 102, 1021-1024 (2008). doi:10.1007/s00436-007-0870-7

26. PK Prasad, V Tandon, DK Biswal, LM Goswami, A Chatterjee, Use of sequence motifs as barcodes and secondary structures of internal transcribed spacer 2 (ITS2, rDNA) for identification of the Indian liver fluke, Fasciola (Trematoda: Fasciolidae). Bioinformation. 3, 314-320 (2009)

27. RD Adlard, SC Barker, D Blair, TH Cribb, Comparison of the second internal transcribed spacer (ribosomal DNA) from populations and species of Fasciolidae (Digenea). Int J Parasitol. 23, 423-425 (1993). doi:10.1016/00207519(93)90022-Q

28. SK Semyenova, EV Morozova, GG Chrisanfova, W Gorokhov, IA Arkhipov, AS Moskvin, SO Movsessyan, AP Ryskov, Genetic differentiation in Eastern European and Western Asian populations of the liver fluke, Fasciola hepatica, as revealed by mitochondrial nad1 and cox1 genes. J Parasitol. 92, 525-530 (2006). doi:10.1645/GE-673R.1

29. JL Boore, Animal mitochondrial genomes. Nucleic Acids Res. 27, 1767-1780 (1999). doi:10.1093/nar/27.8.1767

30. TH Le, D Blair, DP McManus, Complete DNA sequence and gene organization of the mitochondrial genome of the liverfluke, Fasciola hepatica L. (Platyhelminthes; Trematoda). Parasitology. 123, 609-621 (2001) 
31. N Galtier, B Nabholz, S Glémin, GD Hurst, Mitochondrial DNA as a marker of molecular diversity: a reappraisal. Mol Ecol. 18, 4541-4550 (2009). doi:10.1111/j.1365-294X.2009.04380.x

32. M Santamaria, C Lanave, S Vicario, C Saccone, Variability of the mitochondrial genome in mammals at the inter-species/intra-species boundary. Biol Chem. 388, 943-946 (2007). doi:10.1515/BC.2007.121

33. $M W$ Li, RQ Lin, HQ Song, RA Sani, XY Wu, XQ Zhu, Electrophoretic analysis of sequence variability in three mitochondrial DNA regions for Ascaridoid parasites of human and animal health significance. Electrophoresis. 29, 2912-2917 (2008)

34. MV Periago, MA Valero, SM El, K Ashrafi, WA El, MY Mohamed, M Desquesnes, F Curtale, S Mas-Coma, First phenotypic description of Fasciola hepatica/Fasciola gigantica intermediate forms from the human endemic area of the Nile Delta, Egypt. Infect Genet Evol. 8, 51-58 (2008). doi:10.1016/ j.meegid.2007.10.001

35. XQ Zhu, M Podolska, JS Liu, HQ Yu, HH Chen, ZX Lin, CB Luo, HQ Song, RQ Lin, Identification of Anisakid nematodes with zoonotic potential from Europe and China by single-strand conformation polymorphism analysis of nuclear ribosomal DNA. Parasitol Res. 101, 1703-1707 (2007). doi:10.1007/ s00436-007-0699-0

36. XQ Zhu, RB Gasser, NB Chilton, DE Jacobs, Molecular approaches for studying Ascaridoid nematodes with zoonotic potential, with an emphasis on Toxocara species. J Helminthol. 75, 101-108 (2001)

37. RB Gasser, Molecular tools-advances, opportunities and prospects. Vet Parasitol. 136, 69-89 (2006). doi:10.1016/j.vetpar.2005.12.002

38. S Alasaad, CQ Huang, QY Li, JE Granados, C Garcia-Romero, JM Perez, XQ Zhu, Characterization of Fasciola samples from different host species and geographical localities in Spain by sequences of internal transcribed spacers of rDNA. Parasitol Res. 101, 1245-1250 (2007). doi:10.1007/s00436-007-0628-2

39. RM Vara-Del, H Villa, M Martinez-Valladares, FA Rojo-Vazquez, Genetic heterogeneity of Fasciola hepatica isolates in the northwest of Spain. Parasitol Res. 101, 1003-1006 (2007). doi:10.1007/s00436-007-0574-z

40. G Dinler, H Budak, Analysis of expressed sequence tags (ESTs) from Agrostis species obtained using sequence related amplified polymorphism. Biochem Genet. 46, 663-676 (2008). doi:10.1007/s10528-008-9181-7

41. XY Han, LS Wang, OY Shu, ZA Liu, SX Xu, T Tetsumura, Molecular characterization of tree peony Germplasm using sequence-related amplified polymorphism markers. Biochem Genet. 46, 162-179 (2008). doi:10.1007/ s10528-007-9140-8

42. S Alasaad, QY Li, RQ Lin, P Martin-Atance, JE Granados, P Diez-Banos, JM Perez, XQ Zhu, Genetic variability among Fasciola hepatica samples from different host species and geographical localities in Spain revealed by the novel SRAP marker. Parasitol Res. 103, 181-186 (2008). doi:10.1007/s00436008-0952-1

43. KR Gunasekar, AK Tewari, C Sreekumar, SC Gupta, JR Rao, Elucidation of genetic variability among different isolates of Fasciola gigantica (giant liver fluke) using random-amplified polymorphic DNA polymerase chain reaction. Parasitol Res. 103, 1075-1081 (2008). doi:10.1007/s00436-008-1095-0

44. SM Walker, PA Prodohl, HL Fletcher, RE Hanna, V Kantzoura, EM Hoey, A Trudgett, Evidence for multiple mitochondrial lineages of Fasciola hepatica (liver fluke) within infrapopulations from cattle and sheep. Parasitol Res. 101, 117-125 (2007). doi:10.1007/s00436-006-0440-4

45. A Marcilla, MD Bargues, S Mas-Coma, A PCR-RFLP assay for the distinction between Fasciola hepatica and Fasciola gigantica. Mol Cell Probes. 16, 327-333 (2002). doi:10.1006/mcpr.2002.0429

46. S Alasaad, RC Soriguer, M Abu-Madi, A El Behairy, PD Baños, A Píriz, J Fickel, $\mathrm{XQ}$ Zhu, A fluorescence-based polymerase chain reaction-linked singlestrand conformation polymorphism (F-PCR-SSCP) assay for the identification of Fasciola spp. Parasitol Res. 108, 1513-1517 (2011). doi:10.1007/s00436010-2209-z

47. L Ai, SJ Dong, WY Zhang, HM Elsheikha, YS Mahmmod, RQ Lin, ZG Yuan, YL Shi, WY Huang, XQ Zhu, Specific PCR-based assays for the identification of Fasciola species: their development, evaluation and potential usefulness in prevalence surveys. Ann Trop Med Parasitol. 104, 65-72 (2010). doi:10.1179/ $136485910 \times 12607012373713$

48. V Heussler, H Kaufmann, D Strahm, J Liz, D Dobbelaere, DNA probes for the detection of Fasciola hepatica in snails. Mol Cell Probes. 7, 261-267 (1993). doi:10.1006/mcpr.1993.1039

49. R Velusamy, BP Singh, OK Raina, Detection of Fasciola gigantica infection in snails by polymerase chain reaction. Vet Parasitol. 120, 85-90 (2004). doi:10.1016/j.vetpar.2003.11.009
50. MA Cucher, S Carnevale, L Prepelitchi, JH Labbe, C Wisnivesky-Colli, PCR diagnosis of Fasciola hepatica in field-collected Lymnaea columella and Lymnaea viatrix snails. Vet Parasitol. 137, 74-82 (2006). doi:10.1016/j. vetpar.2005.12.013

51. RM Kaplan, JB Dame, GR Reddy, CH Courtney, A repetitive DNA probe for the sensitive detection of Fasciola hepatica infected snails. Int J Parasitol. 25 , 601-610 (1995). doi:10.1016/0020-7519(94)00159-L

52. KG Magalhaes, LK Jannotti-Passos, RL Caldeira, ME Berne, G Muller, OS Carvalho, HL Lenzi, Isolation and detection of Fasciola hepatica DNA in Lymnaea viatrix from formalin-fixed and paraffin-embedded tissues through multiplex-PCR. Vet Parasitol. 152, 333-338 (2008). doi:10.1016/j. vetpar.2007.12.019

53. JW McGarry, PL Ortiz, JE Hodgkinson, I Goreish, DJ Williams, PCR-based differentiation of Fasciola species (Trematoda: Fasciolidae), using primers based on RAPD-derived sequences. Ann Trop Med Parasitol. 101, 415-421 (2007). doi:10.1179/136485907X176508

54. S Alasaad, RC Soriguer, M Abu-Madi, BA El, PD Banos, A Piriz, J Fickel, XQ Zhu, A TaqMan real-time PCR-based assay for the identification of Fasciola spp. Vet Parasitol. 179, 266-271 (2011)

55. G Schweizer, ML Meli, PR Torgerson, H Lutz, P Deplazes, U Braun, Prevalence of Fasciola hepatica in the intermediate host Lymnaea truncatula detected by real time TaqMan PCR in populations from 70 Swiss farms with cattle husbandry. Vet Parasitol. 150, 164-169 (2007). doi:10.1016/j. vetpar.2007.08.006

56. T Notomi, H Okayama, H Masubuchi, T Yonekawa, K Watanabe, N Amino, T Hase, Loop-mediated isothermal amplification of DNA. Nucleic Acids Res. 28, E63 (2000). doi:10.1093/nar/28.12.e63

57. K Nagamine, T Hase, T Notomi, Accelerated reaction by loop-mediated isothermal amplification using loop primers. Mol Cell Probes. 16, 223-229 (2002). doi:10.1006/mcpr.2002.0415

58. L Ai, C Li, HM Elsheikha, SJ Hong, JX Chen, SH Chen, X Li, XQ Cai, MX Chen, XQ Zhu, Rapid identification and differentiation of Fasciola hepatica and Fasciola gigantica by a loop-mediated isothermal amplification (LAMP) assay. Vet Parasitol. 174, 228-233 (2010). doi:10.1016/j.vetpar.2010.09.005

59. S Hurtrez-Boussés, P Durand, R Jabbour-Zahabr, JF Guegan, C Meunier, MD Bargues, S Mas-Coma, F Renaud, Isolation and characterization of microsatellite markers in the liver fluke (Fasciola hepatica). Mol Ecol Notes. 4, 689-690 (2004). doi:10.1111/j.1471-8286.2004.00786.x

60. ND Young, AR Jex, C Cantacessi, RS Hall, BE Campbell, TW Spithill, S Tangkawattana, P Tangkawattana, T Laha, RB Gasser, A portrait of the transcriptome of the neglected trematode, Fasciola gigantica-biological and biotechnological implications. PLoS Negl Trop Dis. 5, e1004 (2011). doi:10.1371/journal.pntd.0001004

61. MW Robinson, R Menon, SM Donnelly, JP Dalton, S Ranganathan, An integrated transcriptomics and proteomics analysis of the secretome of the helminth pathogen Fasciola hepatica: proteins associated with invasion and infection of the mammalian host. Mol Cell Proteomics. 8, 1891-1907 (2009). doi:10.1074/mcp.M900045-MCP200

62. JV Moxon, EJ LaCourse, HA Wright, S Perally, MC Prescott, JL Gillard, J Barrett, JV Hamilton, PM Brophy, Proteomic analysis of embryonic Fasciola hepatica: characterization and antigenic potential of a developmentally regulated heat shock protein. Vet Parasitol. 169, 62-75 (2010). doi:10.1016/j. vetpar.2009.12.031

doi:10.1186/1756-3305-4-101

Cite this article as: Ai et al:: Genetic characterization, species differentiation and detection of Fasciola spp. by molecular approaches. Parasites \& Vectors 2011 4:101. 